\title{
ESG and reputation: The case of sanctioned Italian banks
}

\author{
Pina Murè $^{1}$ | Marco Spallone ${ }^{2}$ | Fabiomassimo Mango ${ }^{1}$ | Stefano Marzioni ${ }^{3}$ ( ) | \\ Lucilla Bittucci $^{1}$
}

${ }^{1}$ Department of Management, Sapienza Università di Roma, Rome, Italy

${ }^{2}$ Department of Philosophical, Pedagogical and Quantitative-Economic Sciences, Università Chieti Pescara-Luiss CASMEF, Pescara, Italy

${ }^{3}$ Department of Business and Management, Luiss CASMEF, Roma, Italy

\section{Correspondence}

Stefano Marzioni, Department of Business and Management, Luiss CASMEF, viale Romania

32, Roma 00187 Italy.

Email: smarzioni@luiss.it

\begin{abstract}
The aim of this paper is to investigate whether banks adopt Environmental, Social, and Governance (ESG) practices to reduce reputational damage due to financial penalties and whether the adoption of ESG factors can reduce the probability to receive sanctions. This study extends a previous research (Guerello et al., North American Journal of Economics and Finance, 2018, 48, 591-612) by including ESG scores as determinant of the probability to be sanctioned. The econometric analyses in this paper are based on a sample of 13 Italian banks for the years 2008-2018 and includes ESG scores provided by both Thomson Reuters and Bloomberg. The research shows that ESG score and the probability of sanctions are positively related. However, a careful analysis of causal directions clarifies the meaning of such positive relationship: receiving financial penalties is detrimental for banks reputations, therefore it's necessary for banks to improve their reputation through the adoption of ESG practices.
\end{abstract}

\section{KEYWORDS}

banking reputation, banks sanctions, CSR, ESG score

\section{1 | INTRODUCTION}

In recent years, banks, financial markets, and public authorities showed a growing attention for sustainable finance. In this view, Environmental, Social, and Governance (ESG) - activities are currently included in the business models of an increasing number of financial intermediaries.

In Europe, the perceived relevance of financial sustainability is mainly due to the commitment of the European Commission to boost the integration of ESG parameters into all aspects of the financial system. For example, among the initiatives put in place by the Commission, the Technical Expert Group on Sustainable Finance and the High-Level Expert Group have been recently established with the aim to assist the EU sustainable regulatory program. In particular, the Technical Expert Group pursues the objective to support the European Commission in developing (a) an EU taxonomy for environmentally sustainable activities (European Commission, 2018), (b) an EU Green Bond Standard in order to guarantee the comparison and the transparency of the Green Bonds, (c) methodologies for EU climate benchmarks and (d) guidelines to improve corporate disclosure on climate related information. On the other side, the High Level Expert Group on sustainable finance is a task force composed by 20 senior experts with the mandate to assist the European Commission in steering the public and private capital to more sustainable investments and to classify the steps that supervisory authorities and institutions should take to ensure the stability of the system from environmental risks. In addition, the European Commission recently published the "Action Plan on Financing Sustainable Growth" to strengthen ESG companies' disclosure and to define a clearer taxonomy of sustainable activities.

The adoption of ESG factors among financial intermediaries is also driven by the fact that all the initiatives introduced by the European Commission will be soon shared by supervisory authorities and will radically change banks' activity. For example, according to the European Banking Authority (2019), banks will soon integrate ESG parameters in their risk processes and credit policies in order to face transitional and physical risks intended respectively as (a) the financial impact due to climate changes and (b) the potential financial loss that can result from the process of adaption toward more environmentally 
sustainable practices (i.e., market sentiment, technological process) (European Central Bank, 2020; Signorini, 2019).

These considerations suggest that this new approach will probably affect the current prudential framework and therefore ESG activities will become strategic for both banks and public authorities. Furthermore, it is widely believed that financial intermediaries should not be considered only as producers of financial values, but also as drivers of a more sustainable development (Wilson, 1999), for which the inclusion of ESG factors in their activities seems to be necessary.

It should be noted that among the causes of the development of ESG practices among financial intermediaries, the financial crisis played a crucial role. Indeed, the crisis has severely affected the banking system and consequently credit institutions have begun to adopt these practices not honestly but with the aim to mainly re-store their confidence between customers.

Taking into account these considerations - and considering the fact that ESG activities are widely recognized by academic literature (see, among others, Gangi, Daniele, and Varrone (2020), Lin, Zeng, Wang, Zou, and Ma (2016), Gallardo-Vázquez, Valdez-Juarez, and Castuera-Diaz (2019), Dell'Atti, Trotta, lannuzzi, and Demaria (2017)) among the numerous variables that can affect reputation - our aim is to analyse how the adoption of ESG practices impacts on banks' probability of sanctions and to explore the relationship between ESG and reputation on Italian sanctioned banks. In that regard, we aim to investigate if the adoption of ESG practices can reduce compliance risk through its reputational effects. Indeed, compliance risk is defined as "the risk of legal or regulatory sanctions, financial loss, or loss to reputation a bank may suffer as a result of its failure to comply with all applicable laws, regulations, codes of conduct and standards of good practice" and therefore as the union of both reputational and financial components (Basel Committee on Banking Supervision (BCBS), 2003).

In this paper we assess the impact of ESG activities on the probability for an Italian bank to incur into a sanction. A similar approach has been followed by Guerello, Murè, Rovo, and Spallone (2018) whose focus is on the impact of balance sheet items and accounting ratios on the probability to be sanctioned. In order to disentangle the relationship between ESG and probability to be sanctioned, we obviously need to control for variables other than ESG that affect such a probability. Therefore, we heavily rely on the analysis in Guerello et al. (2018) and in that we use their selection of accounting ratios and balance sheet items as a starting point for variables selection in our econometric analysis.

The remainder of the paper is structured as follows: Section 2 reviews the relevant literature, Section 3 describes the data used in the econometric analysis, Section 4 provides the empirical evidence supporting our thesis, Section 5 discusses the implications of our results and concludes.

\section{2 | LITERATURE REVIEW}

As for our knowledge, nobody studied the relationship between sanctions and ESG activities, notwithstanding the fact that both sanctions and ESG activities determine reputational effects. As for ESG, literature can be divided in four streams of work.

The first workflow analyses the link between corporate risk and ESG factors: for example, Gangi, Meles, D'Angelo, and Daniele (2018) explore the relationship between environmental engagement and corporate risk on a sample of 142 banks and verify that banks that are more sensitive to environmental issues are also less risky while Sassen, Hinze, and Hardeck (2016) investigate the impact of corporate social performance - intended as ESG - on risk firm. In particular, analyzing idiosyncratic, systemic, and total risk, they find that aggregated ESG score decreases total and idiosyncratic risk while social factor decreases all the three categories of risk. Di Tommaso and Thorton (2020) identify that (a) ESG score is usually associated to a modest reduction in risk taking and that (b) the impact of the ESG depends mainly on board's characteristic while Orlitzky and Benjamin (2001) verify through meta-analysis verify that corporate social performance reduces financial risk.

The second field of work investigates the relationship between ESG factors and corporate performance. On this aspect, Xie, Nozawa, Yagi, Fujii, and Shunaukw (2018) investigate the relationship between corporate efficiency and corporate sustainability in order to determine whether the adoption of the three ESG factors can increase corporate profitability or not; Friede, Busch, and Bassen (2015) - through a study which combined the results of more than 2000 empirical studies - conclude that $90 \%$ of academic studies found a non-negative and stable relationship between corporate financial performance and ESG; Esteban-Sanchez, de la Cuesta-Gonzalez, and Paredes-Gazquez (2017) - on a sample composed by 154 companies affected by the financial crisis - analyse the impact of four dimensions of corporate social performance on corporate financial performance: they find that good corporate governance and good employee policies have a positive effect on corporate financial performance. Finally, relevant is the literature review of Van Beurden and Gossling (2008) which confirm a clear evidence between corporate social responsibility and corporate financial performance.

The third workflow examines the impact of ESG factors on market performance and on portfolio strategies: Verheyden, Eccles, and Feiner (2016) find that ESG screening increases risk-adjusted returns and likewise Sherwood and Pollard (2017) demonstrate that the integration of ESG markets equities in institutional portfolios could provide higher returns for investors. Deng and Cheng (2019) - on a sample of Chinese listed companies - demonstrate a positive relationship between enterprise's ESG indices and its stock market performance.

The last stream of work is focused on the divergence of ESG ratings and measures, and on the need to uniform and standardize this framework across jurisdictions (Berg, Kolbel, \& Rigobon, 2019; Eccles \& Stroehle, 2018; Escrig-Olmedo, Rivera-Lirio, Munoz-Torres, \& Fernandez-Izquierdo, 2017; Huber et al., 2017). In this context, it is worth mentioning an additional stream of work which studies the impact of climate change on banks' activity. In that regard, several studies also confirm that climate change can have a relevant impact on credit management (Georgopoulou et al., 2014) and that a 
standardized prudential framework is necessary to mitigate the potential effects on financial stability (Nieto, 2019). Moreover, some researches state that climate changes can affect not only banks' activity, but also financial stability objectives of central banks (Batten, Sowerbutts, \& Tanaka, 2016; Campiglio et al., 2018; Monnin, 2018).

Regarding sanctions, most of the literature has investigated the relationship between financial penalties and banks' performance in terms of efficiency and productivity (Danisewicz, McGowan, Onali, \& Schaeck, 2018; Guerello et al., 2018; Koster \& Pelster, 2017; Murè, Pesic, \& Lo, 2011), while others have examined the role of financial penalties from a macroeconomic point of view, and in particular their impact on banks' failures (Delis, Staikouras, \& Tsoumas, 2017) and on liquidity and credit channels (Deli, Delis, Hasan, \& Liu, 2016). As for governance, Cotugno, D'Amato, Gallo, and Stefanelli (2017) proves that financial penalties increase board's member expertise. It is worth mentioning a relevant study conducted by Utz (2019) in which the author studies the reliability of ESG assessment in predicting corporate scandals on a sample of international firms ESG ratings are useless in predicting these accidents.

As regarding reputation, several studies have been conducted on the potential relationship between reputation and ethical practices, but as for our knowledge nobody investigated the relationship between ESG, sanctions and reputation: Gangi et al. (2020) investigate on how environmental policies conducted by corporates can affect corporate reputation and consequently risk-adjust profitability, finding that reputation is mainly affected by intangible assets as ESG practices, while Lin et al. (2016) demonstrate that environmental irresponsibility could have negative effects on corporate reputation. Gallardo-Vázquez et al. (2019) examine whether board's orientation toward CSR increases the level of competitiveness and reputation. From a qualitative point of view, relevant are the studies conducted by Ozdora-Aksak, Ferguson, and Atakan-Duman (2016) and Siltaoja (2006). The first one - after a literature review which reveals that the relationship between corporate social responsibility and corporate reputation has been mainly investigated from empirical side - provides a conceptual analysis to identify how academic literature explains the relationship between CSR and organizational reputation, while the second one explore the relationship between the two variables through value theory and find that value priorities are crucial for CSR activities and corporate reputation. Focusing the attention on banking sector, Dell'Atti et al. (2017) confirm a positive relationship between banking reputation and social scores and conclude that sustainable practices are able to strength banks' reputation and similarly Forcadell and Aracil (2017) demonstrate the positive effect of CSR reputation on a sample of banks listed Dow Jones Sustainability Index (DJSI). Closing, Trotta and Cavallaro (2012) examine that reputation is relevant for the banking sector because financial services and operations are mainly based on trust relationship.

\section{3 | ECONOMETRIC ANALYSIS}

The aim of this econometric analysis is to assess the significance and the sign of ESG scores on the probability for a sanction to be inflicted.
In order to understand whether the level of ESG score might affect the probability for a sanction to a bank to occur, we fit the available panel data with the following model based on GMRS:

$$
\text { sanction }_{i, t}=\alpha_{i}+\beta x_{i, t}+\varepsilon_{i, t} \text {, }
$$

where $\alpha_{i}$ stands for the unobserved time invariant effect and $x_{i, t}$ are the bank-level explanatory variables, including accounting items, and ESG indicators. It is worth to remark that throughout the paper we estimate a unique model across different sets of explanatory variables and with different estimators, namely a panel probit, and a pooled instrumental variables probit.

Let $y_{i, t}=0$ if sanction $_{i, t}=0$ and Let $y_{i, t}=1$ if sanction $_{i, t}>0$. The probability of a penalty to be inflicted, conditional to the realization of the explanatory variables, is

$$
\operatorname{Pr}\left[y_{i, t}=1 \mid x_{i, t}, \alpha_{i}, \beta\right]=\Phi\left(\alpha_{i}+\beta x_{i t}\right)
$$

where $\Phi$ is the standard normal cumulative density function, that is, $\Phi\left(\alpha_{i}+\beta x_{i t}\right)=\int_{-\infty}^{\alpha_{i}+\beta x_{i t}} \phi(z) d z$. The panel estimator is a non-linear random-effect panel probit estimator based on the assumption of independence between the time-invariant individual effects and explanatory variables, as well as on the independence of regressors across banks and over time. The dependent variable of our analysis is the penalty inflicted as an event, rather than their monetary magnitude. Therefore, we use an indicator variable $s_{i, t}$ which is equal to one if a penalty is inflicted to the $i$-th bank in period $t$, and zero elsewhere.

Our dataset includes data from selected Italian banks from 2008 until 2018. Banks are selected based on the availability of ESG indicators, as provided by Reuters, and Bloomberg. Banks for which a Bloomberg ESG indicator is available are 10, whereas those for which a Reuters indicator is available are 13.

ESG scores used in our research are retrieved by Thomson Reuters and Bloomberg datasets for available Italian banks. Both indexes represent a synthesis of a multi-dimensional array of information on the three ESG areas (Environmental, Social, and Governance), both numeric, and qualitative. Both combine the available information by means of proprietary methodologies. The Thomson Reuters ESG score provides a quantile-based ranking, whereas the Bloomberg ESG score spans from 0 to 100 , according to the level of disclosure of a company. For an overview of how Thomson Reuters ESG scores are calculated see Thomson Reuters (2018) - Thomson Reuters ESG score. Data from Thomson Reuters online provider were downloaded on November 25th, 2019. The qualitative Thomson Reuters ESG score is converted to a number on a rank basis. ${ }^{1}$ The information used is based on the ESG score tout court, which does not include the assessment on controversies. ${ }^{2}$

As far as the ESG score from Bloomberg, the audit, and regulatory risk component of the index cannot be ruled out, given the available information. Therefore, in the analyses that are based on the Bloomberg ESG score, we make use of the overall score that includes the audit and regulatory risk component. 
It should be noted that relevant studies confirm a wide divergence among most important rating agencies. Berg et al. (2019) investigate on the top six rating agencies (KLD [MSCI Stats], Sustainalytics, Vigeo Eiris [Moody's], RobecoSAM [SP Global], Asset4 [Refinitiv], $\mathrm{MSCl}$ IVA) and find that raters disagree on both definition and measurement of the different aspects of ESG. Also Semenova and Hassel (2015) analyses the consistent of MSCI ESG STATS, Thomson Reuters ASSET4 and Global Engagement Services (GES) and confirm that the ratings have common dimension but on aggregated basis they diverge while Post, Rahman, and Rubow (2011) in their study on green governance confirm the debate on the contruction on the score provided by KLD.

Figure 1 shows the number of sanctions inflicted to the banks, whose ESG score is available. It can be observed that after the peak of the financial crisis in 2008, the number of sanctions peaks as well, followed by a decline until 2013. In 2014 a new increasing trend starts, reaching new peaks in 2017 and 2018.

In order to get a general idea of the phenomenon, aggregate ESG scores are provided as well. Aggregation occurred through simple averaging. In fact, all banks whose ESG score is available in our dataset can be thought of as "significant" in terms of systemic risk, which is a natural aggregation criterion for ESG because of its qualitative nature. Figures 2 and 3 show the dynamics of aggregate ESG scores from the two available sources. It can be observed that both of them show an increasing trend from 2015 on. A significant difference concerns the years from 2008 until 2011, where the Reuters score is rather stable, whereas the Bloomberg score (available from 2009) sharply decreases.

It is worth to remark that the overall level of the ESG score exhibits an increasing trend in the same years of the increasing trend in sanctions. In particular, the two variables tend to increase when penalties are less attributable to a recession and, therefore, are less likely attributable to worsening general condition. Thus, from an aggregate perspective, it could be conjectured that in the initial years of the sample, that is, in the aftermath of the financial crisis, sanctions are related to systemic shocks and therefore do not signal bankspecific critical issues. On the contrary, in the last years sanctions

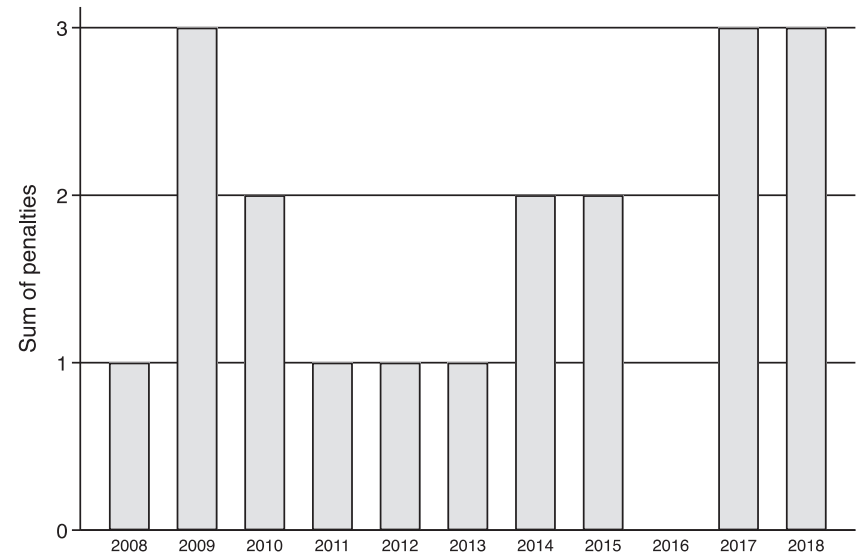

FIGURE 1 Aggregate number of penalties represent symptoms of idiosyncratic bank-specific issues that are therefore signaled to market through penalties.

Figures 3 and 2 are obtained through aggregation from bank-level data and provide only a general information over the compliance to ESG guidelines. Figures 4 and 5, display the dynamics of the ESG score separately for each bank that is used in the econometric analysis below.

The co-variation between the number of sanctions and ESG scores in the last years appears at odds with the nature of ESG compliance strategies. Therefore, the true nature of their relationship with sanctions is worthwhile to be further investigated. In our analysis we extend the approach used in GMRS through the inclusion of ESG indicators among the relevant variables that contribute to determine the probability for a bank of incurring in a penalization. ESG indicators are therefore used to infer their statistical significance relative to other balance sheet items in order to determine the probability for a bank to be sanctioned along with accounting items.

Figures 4 and 5, show the dynamics of the ESG score for each bank who has it available. It can be observed that the behavior of the

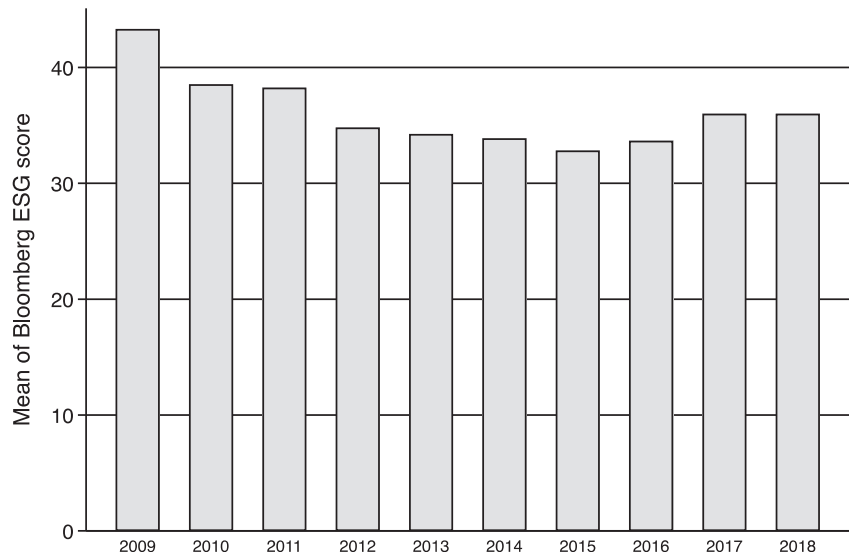

FIGURE 2 Mean of Bloomberg environmental, social, and governance score

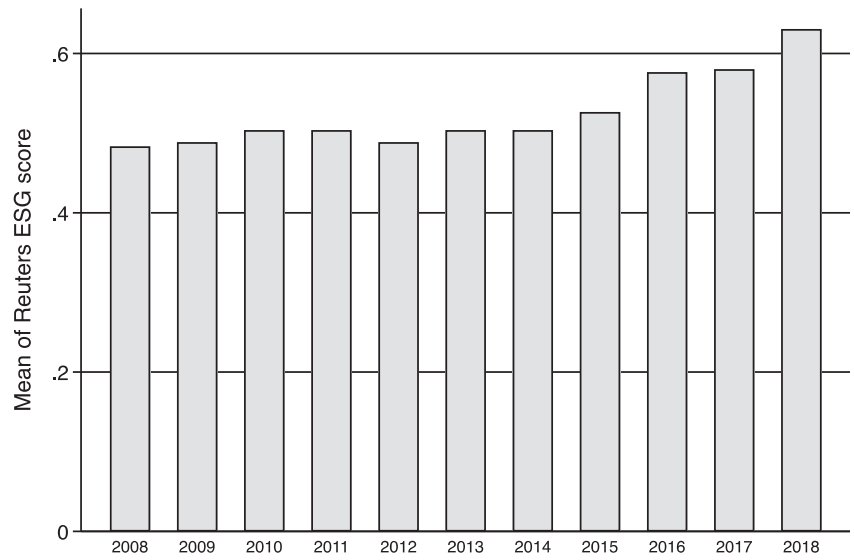

FIGURE 3 Mean of Thomson Reuters environmental, social, and governance score 
FIGURE 4 Thomson Reuters environmental, social, and governance score dynamics by bank
FIGURE 5 Bloomberg environmental, social, and governance score dynamics by bank

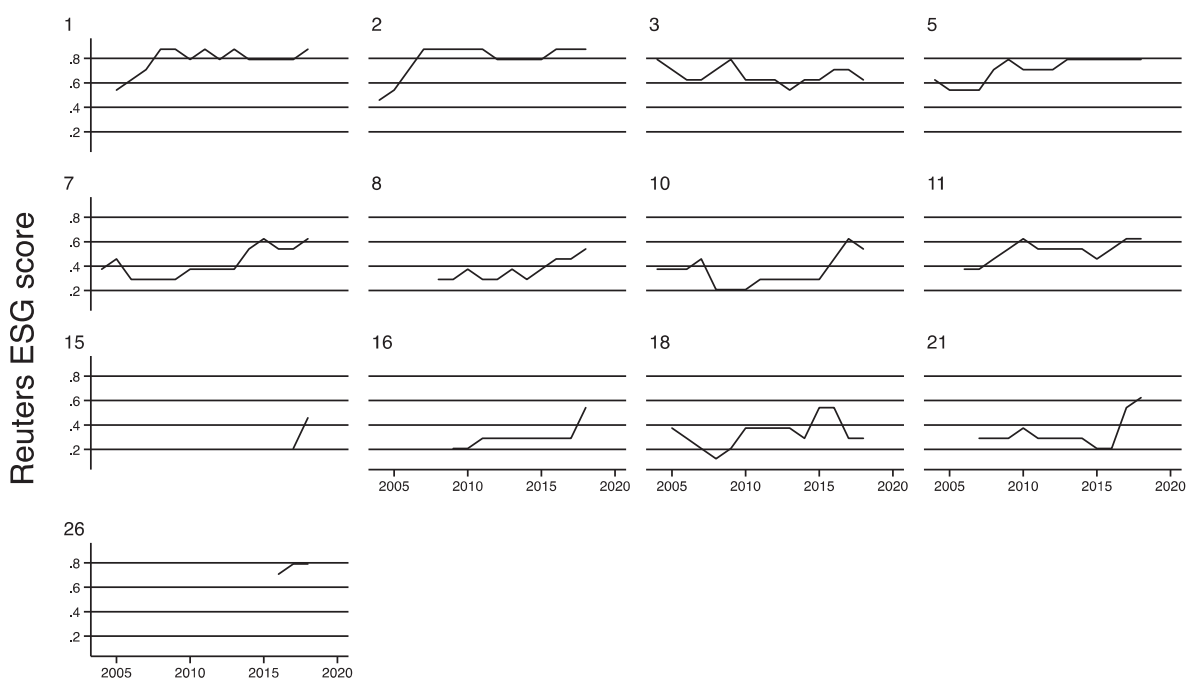

Graphs by bank ID

11

.

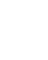


TAB LE 1 List of explanatory variables other than environmental, social, and governance (ESG) score

\begin{tabular}{|ll}
\hline Variable & Key economic area \\
\hline Number of employees & Assets size \\
\hline Total funding (EUR) & Funding and liquidity \\
\hline Total customer deposits (EUR) & Funding and liquidity \\
\hline $\begin{array}{l}\text { Other non-interest bearing liabilities (EUR) } \\
\text { Equity over Total assets (ratio) }\end{array}$ & Equity \\
\hline Tier1 capital (EUR) & Equity \\
\hline $\begin{array}{c}\text { Common equity ratio } \\
\text { Growth of gross loans (\%change) }\end{array}$ & Equity \\
\hline $\begin{array}{c}\text { Impaired loans over average gross loans } \\
\text { (ratio) }\end{array}$ & Equity \\
\hline $\begin{array}{c}\text { Off balance sheet items (EUR) } \\
\text { Securities evaluation reserves on total } \\
\text { assets (ratio) }\end{array}$ & Credit risk \\
\hline $\begin{array}{c}\text { Interest income on loans on average gross } \\
\text { loans (ratio) }\end{array}$ & Efficiency (core) \\
\hline $\begin{array}{c}\text { Pre-impairment operating profit over } \\
\text { average equity (ratio) }\end{array}$ & Efficiency (non-core) \\
\hline $\begin{array}{c}\text { Cost to income ratio } \\
\text { Recurring earning power (EUR) }\end{array}$ & Efficiency (non-core) \\
\hline $\begin{array}{c}\text { Non-interest income over gross revenues } \\
\text { (ratio) }\end{array}$ & Efficiency (non-core) \\
\hline \begin{tabular}{c} 
Return on average equity - ROAE (\% rate) \\
\hline
\end{tabular} & Profitability and taxes \\
\hline
\end{tabular}

regulatory framework focuses on. Therefore, such economic areas are specifically designed to best represent the Italian regulatory framework. Such key economic areas are reported in the third column of Table 1. According to the selected key economic areas, Guerello et al. (2018) select 22 variables among balance sheet items and ratios, covering all the key areas with at least two items. In that research the selected accounting items are the ones with the highest explanatory power. In the present paper the set of variables identified in Guerello et al. (2018) is further scaled down through elimination of the items with the smaller explanatory power. The scaling-down process is carried on conditionally on the representativeness of each key area. We estimated the baseline model using the explanatory variables selected in order to keep as much as possible the relative weight of each economic area that are considered in as in Guerello et al. (2018). Since selection is based on key economic areas, and therefore each variable belongs to small groups composed at most by two or three variables, the statistical significance is based only on the $t$-test.

The "rate of growth of gross loans" provides information on a bank's commercial assets trend and, therefore, on a bank's core assets soundness. The common equity over equity, where the common equity is defined as Common Shares and Premium + Treasury Shares + Stock Options + Retained Earnings + Statutory Reserves (renamed "Common equity" ratio) and the difference between Total Liabilities and Total Interest Earning Liabilities (renamed "Other non-interest bearing liabilities") provide information on both equity structure and the composition of funding. The "number of employees" allows to control for the size of the bank. As far as liquidity indicators, we use "total funding" and "total customers deposits." The "equity-over-total-assets" ratio represents an indicator of financial soundness and leverage. The "Tier1 capital" variable is probably the most important regulatory capital parameter and therefore represents a core measure of financial strength.

The "impaired loans over average gross loans" ratio represents a measure of coverage of loans impairment.

The level of "off balance sheet items" provides information on overall riskiness since it is related to securitizations and other structured operations. The "securities evaluation reserves on total assets" ratio is an indicator for the relevance of trading risk. The "interest income on loans on average gross loans" ratio is an indicator for core profitability, whereas the "pre-impairment operating profit over average equity" ratio provides information on a bank's overall ability to generate profits. The "cost to income" ratio is an indicator of overall internal efficiency. The recurring earning power represents the recurring pre-provision income. The "non-interest income over gross revenues" ratio measures a bank's business orientation. The return on average equity (ROAE) is one of the most common profitability indexes. The relationship between the variables and the performance of a bank in the specific economic area are also extensively discussed in the original paper by Guerello et al. (2018).

\section{4 | EMPIRICAL EVIDENCE}

Table 2 shows the result of the panel estimation for different specifications of the model, where groups of regressors are in turn eliminated in order to test the robustness of the model. As explained in details in the previous section, the baseline specification includes many of the variables used in GMRS, keeping constant the relative weight of the economic key areas, whereas other specifications make use of fewer explanatory variables.

Model 1 includes regressors that are relevant in the model for sanctions in Guerello et al. (2018). Such groups of regressors are a subset of those used in the main estimations in the original model: some of them have been excluded on the basis of their statistical significance, while keeping an adequate representation of the main operational areas of a bank. Table 2 shows the estimated raw coefficients obtained by using a panel random effect estimator and the Thomson Reuters ESG score. In column (1) estimations of the model with the full set of selected regressors but the ESG score are reported, while in column (2) the ESG score is included among regressors. According to the information criteria reported in the footer of the table, the model they includes the ESG score is the best performing one. The coefficient attached to the ESG score is statistically significant at a $10 \%$ significance level (the $p$-value is equal to .072) and its sign is positive. Moreover, as shown in Table 3, according to the baseline model specification - that is, column (2) $95.4 \%$ of banks are correctly classified, whereas the model without ESG score classifies correctly $92.6 \%$ of observed banks.

Columns (3)-(6) report estimates of different specifications, made essentially as robustness checks. It can be observed that the 
TABLE 2 Panel estimation raw coefficients, $p$-values between parentheses

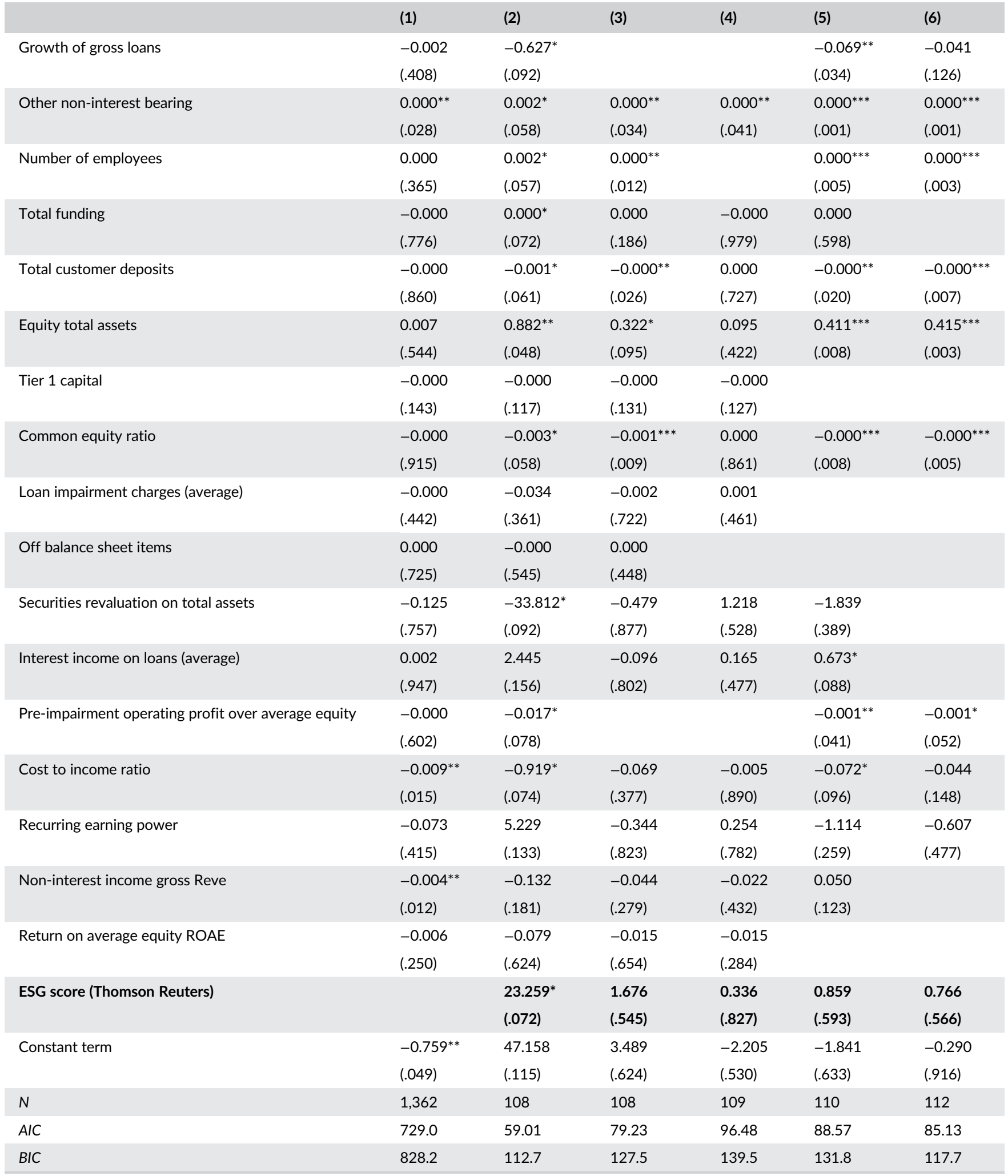

Note: ${ }^{*}<.10,{ }^{* *}<.05,{ }^{* * *}<.01$.

information criteria suggest that none of the specifications performs better than the one reported in column (2). Among the specifications other than (2), the coefficient attached to the ESG score is positive, despite not statistically significant. It is worth to remark that in all specifications with a lower number of regressors the magnitude of the ESG coefficient is lower than with the full number of regressors. This 
TABLE 3 Outcomes classification of baseline specification

\begin{tabular}{|ccc|} 
& Sanction $=\mathbf{0}$ & Sanction $=\mathbf{1}$ \\
\hline Probability $<0.5$ & 91 & 3 \\
\hline Probability $\geq 0.5$ & 2 & 12 \\
\hline
\end{tabular}

TABLE 4 Pooled IV probit estimator

\begin{tabular}{|c|c|c|c|}
\hline & (7) & (8) & (9) \\
\hline $\begin{array}{l}\text { ESG score (Thomson } \\
\text { Reuters) }\end{array}$ & $\begin{array}{l}3.774^{* *} \\
(.040)\end{array}$ & $\begin{array}{l}3.353 \\
(.105)\end{array}$ & $\begin{array}{l}2.729 * \\
(.066)\end{array}$ \\
\hline Other non-interest bearing & $\begin{array}{l}0.000^{* * *} \\
(.000)\end{array}$ & $\begin{array}{l}0.000^{* * *} \\
(.002)\end{array}$ & $\begin{array}{l}0.000^{* * *} \\
(.002)\end{array}$ \\
\hline Total funding & $\begin{array}{l}-0.000 \\
(.600)\end{array}$ & $\begin{array}{l}-0.000 \\
(.982)\end{array}$ & \\
\hline Total customer deposits & $\begin{array}{l}0.000 \\
(.359)\end{array}$ & $\begin{array}{l}-0.000^{* *} \\
(.036)\end{array}$ & $\begin{array}{l}-0.000^{* * *} \\
(.002)\end{array}$ \\
\hline Equity total assets & $\begin{array}{l}0.066 \\
(.545)\end{array}$ & $\begin{array}{l}0.403^{* * *} \\
(.007)\end{array}$ & $\begin{array}{l}0.445^{* * *} \\
(.003)\end{array}$ \\
\hline Tier 1 capital & $\begin{array}{l}-0.000^{* * *} \\
(.000)\end{array}$ & & \\
\hline Common equity ratio & $\begin{array}{l}-0.000 \\
(.990)\end{array}$ & $\begin{array}{l}-0.000^{* * *} \\
(.000)\end{array}$ & $\begin{array}{l}-0.000^{* * *} \\
(.001)\end{array}$ \\
\hline $\begin{array}{l}\text { Loan impairment charges } \\
\text { (average) }\end{array}$ & $\begin{array}{l}0.001 \\
(.158)\end{array}$ & & \\
\hline $\begin{array}{l}\text { Securities revaluation on } \\
\text { total assets }\end{array}$ & $\begin{array}{l}1.278 \\
(.580)\end{array}$ & $\begin{array}{l}-1.012 \\
(.689)\end{array}$ & \\
\hline $\begin{array}{l}\text { Interest income on loans } \\
\text { (average) }\end{array}$ & $\begin{array}{l}0.143 \\
(.357)\end{array}$ & $\begin{array}{l}0.825^{* *} \\
(.022)\end{array}$ & \\
\hline Cost to income ratio & $\begin{array}{l}-0.015 \\
(.615)\end{array}$ & $\begin{array}{l}-0.081 \\
(.129)\end{array}$ & $\begin{array}{l}-0.070^{* * *} \\
(.009)\end{array}$ \\
\hline Recurring earning power & $\begin{array}{l}0.075 \\
(.881)\end{array}$ & $\begin{array}{l}-1.349 \\
(.119)\end{array}$ & $\begin{array}{l}-1.240^{* *} \\
(.031)\end{array}$ \\
\hline $\begin{array}{l}\text { Non-interest income gross } \\
\text { revenues }\end{array}$ & $\begin{array}{l}-0.044 \\
(.116)\end{array}$ & $\begin{array}{l}0.041 \\
(.344)\end{array}$ & \\
\hline $\begin{array}{l}\text { Return on average equity } \\
\text { ROAE }\end{array}$ & $\begin{array}{l}-0.017^{* * *} \\
(.002)\end{array}$ & & \\
\hline Growth of gross loans & & $\begin{array}{l}-0.083^{* * *} \\
(.003)\end{array}$ & $\begin{array}{l}-0.043^{* *} \\
(.028)\end{array}$ \\
\hline Number of employees & & $\begin{array}{l}0.000^{* * *} \\
(.004)\end{array}$ & $\begin{array}{l}0.000^{* * *} \\
(.003)\end{array}$ \\
\hline $\begin{array}{l}\text { Pre-impairment operating } \\
\text { profit over average equity }\end{array}$ & & $\begin{array}{l}-0.001^{*} \\
(.089)\end{array}$ & $\begin{array}{l}-0.001^{* *} \\
(.029)\end{array}$ \\
\hline Constant term & $\begin{array}{l}-1.355 \\
(.698)\end{array}$ & $\begin{array}{l}-2.304 \\
(.526)\end{array}$ & $\begin{array}{l}1.075 \\
(.635)\end{array}$ \\
\hline$N$ & 101 & 102 & 104 \\
\hline$A I C$ & -128.8 & -124.1 & -116.6 \\
\hline$B I C$ & -102.7 & -97.89 & -90.15 \\
\hline
\end{tabular}

Note: ${ }^{*}<0.10,{ }^{* *}<0.05,{ }^{* * *}<0.01$. suggests that specifications in (3)-(6) do not provide a sufficient representation of the phenomenon at hand.

Despite the absence of the controversies component from the Thomson Reuters score that we used, it is generally true that controversies may affect ESG scores, also indirectly through their impact on other variables. In that case, the relationship between the latent variable "controversy/sanction" and the ESG score would apparently be negative. Therefore, the fact that we get a positive sign between sanctions and ESG is even more striking. In fact, a sanction lowers the ESG index of a bank. Thus, if no reputational effect existed, because of such an endogenous effect we would get a negative (and possibly significant) sign with no statistical explanatory power. Since we get a strong positive estimate, we can conjecture that the reputational effect (i.e., the causal effect from ESG to sanction) is larger than the direct effect.

In order to overcome potential issues related to endogeneity, we fit a model for the relationship between the probability of sanctions and ESG scores by using lagged values of ESG scores as instruments for ESG at current time. In fact, lagged values are correlated with ESG scores at current time, while they cannot be directly or indirectly affected by sanctions occurring in the future.

The model is structurally similar to the one fitted in the previous section, despite the estimator is quite different. In fact, in order to take into account the effect of the instrument, we adopted a pooled probit maximum likelihood estimator by correcting standard errors for intra-group correlation. Moreover, given the reduction in the number of available observations due to the utilization of lags as instruments, we had to reduce the number of coefficients to be estimated in order to keep an adequate ratio between observations and required degrees of freedom. The set of regressors used in the pooled IV probit estimation is described in Table 4. Such groups of regressors are a subset of those used in the main estimations in the previous section. Some of them have been excluded on a statistical significance basis, while still keeping an adequate representations of the main operational areas of a bank.

Results from estimation of such a model are shown in Table 4. We get similar results with the IV model in terms of significance and sign of the ESG regressor. Moreover, the Wald test for exogeneity of specification in column (7) (i.e., the one with the lowest values of the information criteria) reports a statistic equal to 1.15 distributed as a chi-squared with one degree of freedom, thus implying a $p$-value of .28. $p$-values for the same test related to specifications in (8) and (9) are, respectively, .24 and .13, Therefore, the null hypothesis of exogeneity cannot be rejected by a reasonable level of significance,

TAB LE 5 Dumitrescu and Hurlin (2012) Granger non-causality test results

$$
\begin{aligned}
& \text { Z-bar }=9.1082 \\
& \text { Z-bar tilde }=4.2504
\end{aligned}
$$$$
(p \text {-value }=.0000)
$$

$(p$-value $=.0000)$

Note: HO: model linear prediction does not Granger-cause the environmental, social, and governance (ESG) score. H1: model linear prediction does Granger-cause the ESG score for at least one bank. 
TA B LE 6 Dumitrescu and Hurlin (2012) Granger non-causality test results

$\begin{array}{ll}\text { Z-bar }=0.8090 & (p \text {-value }=.4185) \\ \text { Z-bar tilde }=0.0587 & (p \text {-value }=.9532)\end{array}$

Note: HO: The environmental, social, and governance (ESG) score does not Granger-cause model linear prediction. H1: The ESG score does Grangercause model linear prediction for at least one bank. thus undermining the issue of endogeneity as far as the Thomson Reuters ESG score.

According to the coefficients reported in Table 4 as for the IV estimation, the sign of the coefficient attached to the ESG score is robustly positive across all specifications, despite not always statistically significant. It is worth to remark that the specification with the lowest (i.e., the better) values for the information criteria shows a

TABLE 7 Panel estimation using environmental, social, and governance (ESG) score from Bloomberg

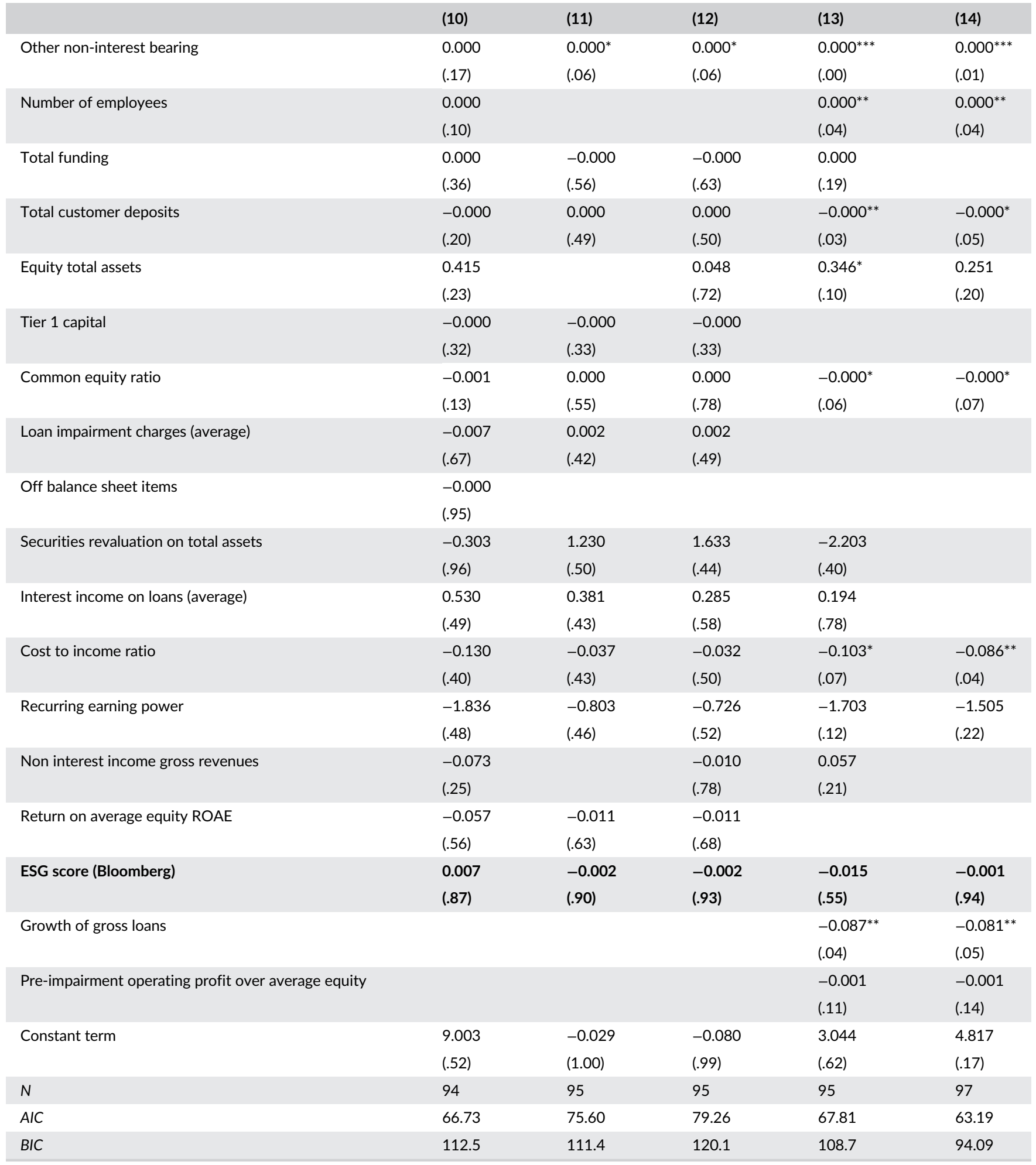




\begin{tabular}{|c|c|c|c|}
\hline & (15) & (16) & (17) \\
\hline \multirow[t]{2}{*}{ ESG score (Bloomberg) } & $0.029^{*}$ & 0.026 & 0.008 \\
\hline & (.07) & (.14) & (.68) \\
\hline \multirow[t]{2}{*}{ Other non interest bearing } & $0.000^{* *}$ & $0.000^{* *}$ & $0.000^{* *}$ \\
\hline & (.03) & (.03) & (.04) \\
\hline \multirow[t]{2}{*}{ Total funding } & -0.000 & $-0.000^{*}$ & -0.000 \\
\hline & $(.21)$ & (.05) & (.80) \\
\hline \multirow[t]{2}{*}{ Total customer deposits } & 0.000 & $0.000^{*}$ & -0.000 \\
\hline & (.14) & (.09) & (.16) \\
\hline \multirow[t]{2}{*}{ Tier 1 capital } & -0.000 & -0.000 & \\
\hline & (.15) & $(.20)$ & \\
\hline \multirow[t]{2}{*}{ Common equity ratio } & 0.000 & 0.000 & -0.000 \\
\hline & (.41) & $(.20)$ & (.16) \\
\hline \multirow[t]{2}{*}{ Loan impairment charges averag } & 0.004 & 0.004 & \\
\hline & (.11) & (.18) & \\
\hline \multirow[t]{2}{*}{ Tot securities tot asset } & 0.644 & -0.084 & -2.243 \\
\hline & (.74) & (.97) & (.44) \\
\hline \multirow[t]{2}{*}{ Interest income on loans avera } & $0.997^{* * *}$ & $1.446^{* *}$ & $1.650^{*}$ \\
\hline & $(.00)$ & $(.02)$ & (.09) \\
\hline \multirow[t]{2}{*}{ Cost to income ratio } & -0.028 & -0.033 & -0.077 \\
\hline & (.43) & (.43) & (.14) \\
\hline \multirow[t]{2}{*}{ Recurring earning power } & -0.659 & -1.024 & -1.979 \\
\hline & $(.47)$ & $(.45)$ & $(.22)$ \\
\hline \multirow[t]{2}{*}{ Return on avg equity ROAE } & 0.006 & 0.004 & \\
\hline & (.84) & (.88) & \\
\hline \multirow[t]{2}{*}{ Equity total assets } & & -0.072 & 0.365 \\
\hline & & (.45) & (.18) \\
\hline \multirow[t]{2}{*}{ Non interest income gross reve } & & 0.031 & 0.099 \\
\hline & & (.56) & (.34) \\
\hline \multirow[t]{2}{*}{ Growth of gross loans } & & & $-0.076^{*}$ \\
\hline & & & (.09) \\
\hline \multirow[t]{2}{*}{ Number of employees } & & & 0.000 \\
\hline & & & (.10) \\
\hline \multirow[t]{2}{*}{ Pre impairment op profit av eq } & & & -0.001 \\
\hline & & & (.14) \\
\hline \multirow[t]{2}{*}{ Constant term } & -3.370 & -4.716 & -5.392 \\
\hline & (.40) & $(.37)$ & (.15) \\
\hline N & 71 & 71 & 71 \\
\hline$A I C$ & 570.2 & 565.7 & 557.5 \\
\hline$B I C$ & 595.1 & 590.6 & 582.4 \\
\hline
\end{tabular}

TABLE 8 Pooled IV estimation using environmental, social, and governance (ESG) score from Bloomberg 
sanction, the causal relationship between ESG score and probability of a sanction can be explained through the need to re-build reputation after a penalty. In this case, the sanction (or the probability to be hit by a sanction, given that the market can possibly interpret publicly available signals as accounting items) induces a bank to a greater effort in order to get a higher ESG score.

In order to support such a hypothesis regarding the causal relationship, Granger causality need to be tested. Empirical evidence to support the reputational interpretation of the positive relationship between ESG score and sanctions is given by the Dumitrescu and Hurlin (2012) DH test on Granger-causality with panel data. The DH test is based on a null hypothesis that ESG score ${ }^{3}$ does not Grangercause the probability for a sanction to be inflicted. The test, therefore, is carried out in order to infer the causality between the Reuters ESG score (Reuters) and the probability predicted by the model are shown in Table 5. Two statistics are reported, namely z-bar, and z-bar tilde. The former can be used in large-size samples for $T$ going to infinity. The latter, instead, has good small sample properties.

It can be observed the z-bar tilde statistics rejects the null hypothesis of the probability of a sanction not to Granger-cause ESG scores with an extremely high statistical significance. The Z-bar statistics supports such a result, despite in short panels the former exhibits higher small-sample performances. Interestingly, the same test does not support the inverse causal relationship, that is, ESG Grangercausing the probability of a sanction, as shown in Table 6.

The econometric analysis of data, therefore, underpins the initial conjecture based on the covariation of aggregate ESG scores and number of sanctions in the recent years. In particular, when sanctions are inflicted many years later than the systemic shocks occurred during the financial crisis, they tend to signal bank-specific critical issues. Therefore, reputation building appears to be a plausible reason for the increase in the ESG overall score. In particular, a positive relationship between ESG and sanctions is documented at a bank-level. Nevertheless, despite the stability of the positive sign attached to ESG when penalties are the dependent variables, significance is low. One possible reason, along with the low number of observations, is that once the market recognizes that a bank is more likely to be sanctioned (or is actually sanctioned indeed), the bank itself tends to implement ESG-compliant strategies in order to recover from the implications of the bad signal. In fact, the estimated latent linear process determining the probability of a sanction is likely to cause (in accordance with Granger's definition of causality) the implementation of ESG strategies, with the purpose of reducing the stigma from potential or actual sanctions.

In Tables 7 and 8 are reported similar estimation procedures of the model using ESG scores from Bloomberg, across different estimators (panel probit and pooled IV probit) and different sets of explanatory variables. Since the number available observations is even smaller than for Thomson Reuters ESG scores, results should be used very cautiously and we limit the discussion to some robustness check for the previous estimations. Moreover, contrarily to the Thomson Reuters ESG score, given the available information, we were not able to eliminate the audit and regulatory risk included by construction in the index. Thus, endogeneity may be a serious issue in such estimations. As shown in Tables 7 and 8, it is apparent that ESG coefficients have a smaller magnitude than in the Thomson Reuters case and are almost generally not statistically significant. Moreover, their sign is not stable across specifications. Such differences with respect to the estimates obtained using Thomson Reuters scores can be related to the direct influence of sanctions and general regulatory issues included in the index. Once we instrument ESG by its past value, the coefficient turns steadily positive, despite not always significant, and with a relatively small magnitude. It should be remarked that the Wald tests (not reported) for exogeneity in two specifications out of three (namely those reported in columns (15) and (16) it Table 8 soundly reject the null hypotheses of exogeneity in the model, thus supporting the need for an adequate instrument in order to correctly assess the impact of ESG on the probability of sanctions.

\section{5 | CONCLUSION}

The aim of our research was to analyse the impact of ESG score on banks' probability of sanction. Our choice is motivated by the commitment of international institutions and supervisory authorities to incentivize the phenomenon of sustainable finance (including the integration of ESG parameters) into all aspects of financial system. In this context, banks could play a crucial role in transferring financial resource toward social and environmental projects in order to contribute to sustainable and economic development.

The policy strategies promoted by the European Commission, will become soon regulatory frameworks and they could radically change banks' activity. In particular, banks shall integrate ESG parameters in their strategies and in their risk management processes in order to face transitional and material risks related to climate change. In this context, financial intermediaries will have to set up governance systems, adequate internal controls, as well as to develop appropriate long-term analyzes to determine the impact of the climate risks and to integrate ESG in their business's strategies. In this perspective, banks have to involve ESG factors in their compliance processes so much to modify their financial strategies with the aim to guarantee long-term value creation.

The present study shows that ESG score and the probability of sanctions are positively related, which is quite surprising as sustainable strategies in most of the literature are associated with virtuous behaviors. The positive sign of the relationship between ESG and penalty infliction is robust to a number of model specifications and estimators. Moreover, despite the low number of observations available, such a relationship is quite significant in statistical terms. The inverse causal relationship between the two variables is a very peculiar point in our analysis. In particular, since we test the hypothesis that being sanctioned has a positive impact on the banks level of ESG score, a positive relationship between ESG and probability for a sanction to be inflicted, can be explained on a reputational basis. In fact, after receiving financial penalties it's necessary for banks to improve their reputation through the adoption of sustainable and impact-oriented practices. Through the Dumitrescu and Hurlin (2012) test, we have 
evidence that ESG score is Granger-caused by the probability of a penalty to be inflicted. Therefore, a reputational channel it seems that a reputational channel is already active and the regulator may find useful. At the end, we can affirm that the integration of ESG criteria is important not only for a sustainable development but also to correct dishonest practices.

It is worth to remark that the focus of our analysis is how ESG affect sanctions, we are not specifically investigating how ESG react to sanctions since, as pointed out above, controversies may also be included into the ESG index by construction. Moreover, our model should not simply be inverted (i.e., the dependent, and the independent variable should not be interchanged). In fact, in determining the impact of ESG on the probability of sanctions, we control for accounting ratios that Guerello et al. (2018) have shown to determine the probability of a sanction. Hence, we disentangle the very peculiar nature of the relationship between ESG and sanctions through a model for the probability of sanction, showing that the more likely causal effect is based on reputation rather than deterrence. We show that, despite the limited availability of observations, there exists measurable evidence of the causal direction being from ESG to sanctions and not vice versa. Therefore, a natural directions for further research are represented by cross-country extension to banks operating in countries other than Italy and cross-section extension, involving financial institution other than banks. Such promising extension are left for future research.

\section{ORCID}

Stefano Marzioni (D) https://orcid.org/0000-0003-2797-3008

\section{ENDNOTES}

1 The qualitative rankings have been converted to numbers between 0 and 1 based on the score range conversion information provided in Thomson Reuters (2018).

2 The so-called "combined ESG score" by Thomson Reuters, instead, includes the rating on controversies and is not considered in our analyses.

${ }^{3}$ In this test, only the Reuters ESG score has been used. The DH test requires a strongly balanced panel, therefore it is inapplicable to the model specification with Bloomberg ESG score due to unavailability of data for the in each year.

\section{REFERENCES}

Batten, S., Sowerbutts, R., \& Tanaka, M. (2016). Let's Talk About the Weather: The Impact of Climate Change on Central Banks, Bank of England Working Paper No. 603.

BCBS, (2003), The compliance function in banks.

Berg, F., Kolbel, J. F., \& Rigobon, R. (2019). Aggregate confusion: The divergence of ESG Ratings, MIT Sloan School of Management, MIT Sloan School Working Paper 5822-19.

Campiglio, E., Dafermos, Y., Monnin, P., Ryan-Collins, J., Schotten, G., \& Tanaka, M. (2018). Climate change challenges for central banks and financial regulators. Nature Climate Change, 8, 462-468.

Cotugno, M., D'Amato, A., Gallo, A., \& Stefanelli, V. (2017). On the Effectiveness of Supervisory Enforcement Actions: How Do Banks Board Reacts, Atti del convegno Estivo ADEIMF 2017, September, University of Roma Tre, Rome.
Danisewicz, P., McGowan, D., Onali, E., \& Schaeck, K. (2018). The real effects of banking supervision: Evidence from enforcement actions. Journal of Financial Intermediation, 35, 86-101.

Deli, Y., Delis, M. D., Hasan, I., \& Liu, L. (2016). Bank Enforcement Actions and the Terms of Lending, Bank of Finland Research Discussion paper 23.

Delis, M. D., Staikouras, P., \& Tsoumas, C. (2017). Formal enforcement actions and bank behaviour. Management Science, 63(4), 959-987.

Dell'Atti, S., Trotta, A., lannuzzi, A. P., \& Demaria, F. (2017). Corporate social responsibility engagement as a determinant of Bank reputation: An empirical analysis. Corporate Social Responsibility and Environmental Management, 24(6), 589.

Deng, X., \& Cheng, X. (2019). Can ESG indices improve the enterprises' stock market performance?-An empirical study from China. Sustainability, 11(17), 4765.

Di Tommaso, C., \& Thorton, J. (2020). Do ESG scores effect bank risk taking and value? Evidence from European banks. Corporate Social Responsibility and Environmental Management, 27(5), 2286-2298.

Dumitrescu, E. I., \& Hurlin, C. (2012). Testing for granger non-causality in heterogeneous panels. Economic Modeling, 29(4), 1450-1460.

Eccles G. R., \& Stroehle C. J. (2018). Exploring Social Origins in the construction of ESG measure.

Escrig-Olmedo, E., Rivera-Lirio, J. M., Munoz-Torres, M. J., \& FernandezIzquierdo, M. A. (2017). Integrating multiple ESG investors' preferences into sustainable investment: A fuzzy multicriteria methodological approach. Journal of Cleaner Production, 162, 1334-1345.

Esteban-Sanchez, P., de la Cuesta-Gonzalez, M., \& Paredes-Gazquez, J. D. (2017). Corporate social performance and its relation with corporate financial performance: International evidence in the banking industry. Journal of Cleaner Production, 162, 1102-1110.

European Banking Authority. (2019). Action plan on sustainable finance.

European Central Bank. (2020). Guide on climate-related and environmental risks. Supervisory expectations relating to risk management and disclosure.

European Commission. (2018). Action Plan: Financing Sustainable Growth.

Forcadell, F. J., \& Aracil, E. (2017). European banks' reputation for corporate social responsibility. Corporate Social Responsibility and Environmental Management, 24(1), 1-14.

Friede, G., Busch, T., \& Bassen, A. (2015). ESG and financial performance: Aggregated evidence from more than 2000 empirical studies. Journal of Sustainable Finance and Investments, 5(4), 210-233.

Gallardo-Vázquez, D., Valdez-Juarez, L. E., \& Castuera-Diaz, A. M. (2019). Corporate social responsibility as an antecedent of innovation, reputation, performance, and competitive success: A multiple mediation analysis. Sustainability, 11(20), 5614. https://doi.org/10.3390/ su11205614

Gangi, F., Daniele, L. M., \& Varrone, N. (2020). How do corporate environmental policy and corporate reputation affect risk-adjusted financial performance? Business Strategy and the Environment, 29, 1975-1991.

Gangi, F., Meles, A., D'Angelo, E., \& Daniele, L. M. (2018). Sustainable development and corporate governance in the financial system: Are environmentally friendly banks less risky? Corporate Social Responsability and Environmental Management, 26, 529-547.

Georgopoulou, E., Mirasgedis, S., Sarafidis, Y., Hontou, V., Gakis, N., Lalas, D., ... Zavras, V. (2014). A methodological framework and tool for assessing the climate change related risks in the banking sector. Journal of Environmental Planning and Management, 58, 874-897.

Guerello, C., Murè, P., Rovo, N., \& Spallone, M. (2018). On the informative content of sanctions. North American Journal of Economics and Finance, 48, 591-612.

Huber, B. M., Comstock, M., Polk, D., \& Wardwell LLP. (2017). ESG reports and ratings: What they are, Why They Matter, Harward Law School Forum on Corporate Governance and Financial Regulation.

Koster, H., \& Pelster, M. (2017). Financial Penalties and bank performance. Journal of Banking \& Finance, 79, 57-73. 
Lin, H., Zeng, S., Wang, L., Zou, H., \& Ma, H. (2016). How does environmental irresponsibility impair corporate reputation? A multi-method investigation. Corporate Social Responsibility and Environmental Management, 23(6), 413-423.

Monnin, P. (2018). Central banks should reflect climate risks in monetary policy operations, SUERF Policy Note, Issue no 41.

Murè, P., Pesic, V., \& Lo, C. C. (2011). Are sanctions effective in improving bank performance? A study on supervision and administrative sanctions upon Italian banks during the 1998-2009 period. CAREFIN Working Paper 23. Centre for Applied Research in Financem Università Commerciale L. Bocconi.

Nieto, M. J. (2019). Banks, climate risk and financial stability. Journal of Financial Regulation and Compliance, 27(2), 243-262.

Orlitzky, M., \& Benjamin, J. D. (2001). Corporate social performance and firm risk: A meta-analytic review. Business \& Society, 40(4), 369-396.

Ozdora-Aksak, E., Ferguson, M. A., \& Atakan-Duman, S. (2016). Corporate social responsibility and CSR fit as predictors of corporate reputation: A global perspective. Public Relations Review, 42, 79-81.

Post, C., Rahman, N., \& Rubow, E. (2011). Green governance: Boards of directors' composition and environmental corporate social responsibility. Business \& Society, 50, 189.

Sassen, R., Hinze, A. K., \& Hardeck, I. (2016). Impact of the ESG factors on firm risks in Europe. Journal of Business Economic, 86, 867-904.

Semenova, N., \& Hassel, L. (2015). On the validity of environmental performance metrics. Journal of Business Ethics, 132, 249-285.

Sherwood, M. W., \& Pollard, J. (2017). The risk-adjusted return potential of integrating ESG strategies into emerging market equities. Journal of Sustainable Finance \& Investments, 8(1), 24-44.

Signorini L. F. (2019). Rischi climatici e regolamentazione prudenziale, Convegno Sviluppo sostenibile, finanza e rischio climatico.

Siltaoja, M. E. (2006). Value priorities as combining core factors between CSR and reputation - A qualitative study. Journal of Business Ethics, 68, 91-111.
Thomson Reuters. (2018). Thomson Reuters ESG scores - Date of issue May 2018.

Trotta, A., \& Cavallaro, G. (2012). Measuring corporate reputation: A framework for Italian banks. International Journal of Economics and Finance Studies, 4(2), 1309-8055.

Utz, S. (2019). Corporate scandal and the reliability of ESG assessments: Evidence from an international sample. Review of Managerial Science, 13, 483-511.

Van Beurden, P., \& Gossling, T. (2008). The worth of values - A literature review on the relation between corporate social and financial performance. Journal of Business Ethics, 82, 407-424.

Verheyden, T., Eccles, R. G., \& Feiner, A. (2016). ESG for all? The impact of ESG screening on return, risk, and diversification. Journal of Applied Corporate Finance, 28(2), 47-55.

Wilson, A. (1999). Social reporting. Developing theory and current practice. In M. Bennett \& P. James (Eds.), (a cura di) Sustainable measures. Evaluation and reporting of environmental and social performance. Sheffield, England: Greenleaf Publishing.

Xie, J., Nozawa, W., Yagi, M., Fujii, H., \& Shunaukw, M. (2018). Do environmental, social and governance activities improve corporate financial performance? Business Strategy and the Environment, 28(2), 286-300.

How to cite this article: Murè $P$, Spallone $M$, Mango $F$, Marzioni S, Bittucci L. ESG and reputation: The case of sanctioned Italian banks. Corp Soc Responsib Environ Manag. 2020;1-13. https://doi.org/10.1002/csr.2047 